\title{
Relationship between type of simple coalworkers' pneumoconiosis and lung function. A nine-year follow-up study of subjects with small rounded opacities
}

\author{
A W MUSK,* J E COTES $\dagger$, CAROL BEVAN, AND M J CAMPBELL \\ From the MRC Pneumoconiosis Unit, Llandough Hospital, Penarth, S Glamorgan CF6 $1 X W, U K$
}

\begin{abstract}
One hundred and twenty-five men who were identified in 1968 as having the simple pneumoconiosis of coalworkers were re-examined nine years later when their mean age was $59 \cdot 6$ years. On both occasions the lung function and response to exercise were assessed. There was no evidence for progression of simple pneumoconiosis between the surveys, but 14 had developed small irregular opacities on their chest radiographs and 28 showed early changes of progressive massive fibrosis (PMF). After allowing for the effects of smoking and of exposure to coal dust, subjects with both $\mathrm{p}$ and $\mathrm{r}$ types of simple pneumoconiosis exhibited a reduced transfer factor compared with subjects having q-type opacities; subjects with r-type opacities also showed an increased pulmonary elastic recoil pressure. The presence of irregular opacities, independent of rounded opacities, was associated with a low transfer factor and decreased slope of phase III of the single breath oxygen test. Subjects who developed PMF between 1968 and 1977 had p or r opacities more often than $q$ opacities: these subjects had an increased pulmonary elastic recoil pressure. The development of PMF was also associated with physiological evidence of airways obstruction. The changes in subjects with $\mathrm{r}$ opacities are consistent with the presence of space occupying lesions that may progress to PMF. Subjects with p opacities have physiological evidence of emphysema as do some subjects with established PMF. Irregular opacities may reflect the presence of both emphysema and diffuse fibrosis. There is need for more morbid anatomical evidence on the underlying pathology.
\end{abstract}

Previous studies of simple pneumoconiosis of coalworkers ${ }^{12}$ have shown that the pulmonary function reflects the type of radiographic opacity; subjects with pinhead (p) opacities have a lower gas transfer capability than subjects with micronodular ( $m$ or $q$ ) or nodular ( $\mathrm{n}$ or $\mathrm{r}$ ) opacities. ${ }^{3}$ This may result from focal emphysema or interstitial fibrosis associated with cystic or honeycomb change developing in subjects with $p$ opacities. ${ }^{1}$ No other relationship between radiographic type of simple pneumoconiosis and pulmonary function has been found consistently. It has not even been possible to show abnormality for conventional tests of pulmonary

\footnotetext{
* Fellow in clinicali sciences (epidemiology), National Health and Medical Research Council of Australia. Present address: Sir Charles Gairdner Hospital, Nedlands, Western Australia, 6009.

†Present address: University Department of Occupational Health and Hygiene, Newcastle upon Tyne.
}

Received 2 December 1980

Accepted 20 January 1981 function in subjects with type "A" large opacities. ${ }^{4}$

To investigate further the relation between type of radiographic opacity and pulmonary function, we have followed up a group of subjects first studied in $1968^{1}$ after a nine year interval. This paper documents the longitudinal changes in pulmonary function and radiographic appearance and looks for functional evidence of differences in pulmonary pathology between radiographic types. The factors contributing to the clinical grade of breathlessness in the same subjects is reported elsewhere. ${ }^{5}$

\section{Subjects}

In 1968150 subjects were identified as having simple coalworkers' pneumoconiosis after routine chest radiography by the National Coal Board; 125 of them participated in a study of the relationship between radiographic type and pulmonary function. Of the 77 subjects with the greatest profusion of small opacities, the 41 with predominantly p opacities had a lower transfer factor per unit alveolar volume and a 
more compliant lung than the 36 subjects with predominantly micronodular ( $\mathrm{m}$ or $\mathrm{q}$ ) or nodular (n or r) opacities. ${ }^{1}$ In 1977 all 125 subjects were traced; 10 had died and 115 were invited to participate in a follow-up study. Four subjects refused to take part, 22 agreed only to answer the respiratory questionnaire and perform spirometry at home, and 89 attended at the pneumoconiosis unit for detailed studies. Some were considered unfit and some refused to participate in particular tests: the number of participants is indicated in the tables of results. Satisfactory chest radiographs were obtained for 87 subjects. Of the 10 men who died between the two surveys, one died from malignant disease and one from trauma. The other deaths were equally divided between cardiovascular and respiratory causes.

\section{Methods}

\section{QUESTIONNAIRE}

The British Medical Research Council questionnaire on respiratory symptoms and smoking habits and a full occupational history was completed by all participants. Grading of breathlessness and of bronchitis was according to the BMRC instruction booklet. ${ }^{6}$

\section{PULMONARY FUNCTION}

Forced expiratory volume in one second $\left(\mathrm{FEV}_{1}\right)$, forced vital capacity (FVC), and maximal expiratory flow volume (MEFV) curves were performed on a digital bellows spirometer. ${ }^{?}$

Total lung capacity (TLC), vital capcity (VC), and residual volume (RV) were measured by the closed circuit helium dilution method. Transfer factor for the lung for carbon monoxide $(\mathrm{Tl})$, multiple breath helium dilution alveolar volumes $\left(\mathrm{V}_{\mathrm{A}}\right)$, and transfer coefficient $\left(\mathrm{KCO}=\mathrm{Tl} / \mathrm{V}_{\mathrm{A}}\right)$ were measured by the method of Ogilvie $e^{a} a^{8}$ on a Resparameter Mark IV (PK Morgan). Diffusing capacity of the pulmonary alveolar membrane $\left(D_{M}\right)$ and capillary blood volume $(\mathrm{Vc})^{9}$ were calculated by estimating $\mathrm{Tl}$ after breathing $100 \% \mathrm{O}_{2}{ }^{4}$

Thoracic gas volume and airways resistance (Raw) by the panting technique ${ }^{10}$ were measured in a constant volume body plethysmograph ${ }^{11}$ to derive specific airway conductance (sGaw).

Transpulmonary pressure was measured using a $10 \mathrm{~cm}$ latex balloon of circumference $3.5 \mathrm{~cm}$ containing $0.4 \mathrm{ml}$ of air and connected to a Mercury pressure transducer (PM6) by a $100 \mathrm{~cm}$ polyethylene tube (id $1 \mathrm{~mm}$ ) using the technique of Milic-Emili et al. ${ }^{12}$ Maximal recoil pressure was taken as the mean of the three highest measurements of four or five separate inflations to TLC. Static expiratory volumetranspulmonary pressure curves were recorded during interrupted expiration from TLC. ${ }^{13}$ Recoil pressure was measured at $50 \% \mathrm{VC}\left(\mathrm{RP}_{50}\right)$, and one litre below TLC $\left(\mathrm{RP}_{1 \mathrm{~L}}\right)$, maximal recoil pressure (RPmax) was also recorded. Pulmonary compliance $\left(C_{E}\right)$ was taken as the slope of the volume pressure curve at one litre above FRC.

Pulmonary conductance-elastic recoil relationships were measured by the method of Colebatch et $a l,{ }^{14}$ flow being recorded on a Fleisch pneumotachograph No 3. Maximal expiratory flow volume (MEFV) curves were also recorded from the body box that was converted to measure volume change by integration of the signal from a screen pneumotachograph mounted in its roof. These MEFV curves were used to construct maximal expiratory flowtranspulmonary pressure curves and to derive a measure of upstream resistance (Rus) at $50 \% \mathrm{VC}$.

Exercise was performed on a Lanooy cycle ergometer. The work load was incrementally increased by 10 watts per min until a nominal 120 watts (1969) or 80 watts (1978) was reached or until the subject stopped because of breathlessness or other discomfort. On two occasions in 1978 exercise was curtailed because of ST-segment changes on the electrocardiogram. Due to the calibration of the ergometer possibly changing between the two surveys the cardiorespiratory responses were related to the physiological load as assessed by the uptake of oxygen and not to the indicated mechanical load. Minute ventilation $\left(\dot{V}_{E}\right)$ was measured with a dry gas meter ${ }^{15}$ and tidal volume by integration of a Mercury pneumotachograph signal. ${ }^{16}$ Cardiac frequency was recorded from lead $V_{5}$ of an electrocardiogram. The ventilation and cardiac frequencies at an oxygen uptake of $45 \mathrm{mmol} / \mathrm{min}(1.0 \mathrm{l} / \mathrm{min})\left(\dot{\mathrm{V}}_{\mathrm{E} 45}\right.$ and $\left.\mathrm{fc}_{45}\right)$ were obtained by interpolation. ${ }^{4}$

Nitrogen index $\left(\mathrm{N}_{2} \mathrm{I}\right)$ which was the slope of phase III of the single breath oxygen test was measured using a modification of Fowler's method ${ }^{17}$; nitrogen concentration being monitored on a mass spectrometer (MS4, Centronics).

Body weight was measured on a balance scale and stature with a Harpenden stadiometer. ${ }^{4}$

COAL DUST EXPOSURE

Indices of exposure to coal dust were calculated using the detailed occupational history and assigning the various job descriptions to a five-point scale of severity of exposure to coal dust: (a) total years in the coal mining industry (TOTYR), $(b)$ total dust exposure (TOTXP), $(c)$ accumulated years in the coal mining industry (ACCUYR), (d) accumulated dust exposure (ACCUXP), and (e) discounted dust exposure (DISXP). For example, suppose that a man's history in coal mining up to the present is $n_{1}$ years at dust level $x_{1}$, followed by $n_{2}$ years at dust 
level $\mathrm{x}_{2}$. Then:

$\begin{aligned} & \text { (a) TOTYR }= \mathrm{n}_{1}+\mathrm{n}_{2} \\ & \text { (b) TOTXP }= \mathrm{n}_{1} \mathrm{x}_{1}+\mathrm{n}_{2} \mathrm{x}_{2} \\ & \text { (c) } \mathrm{ACCUYR}=\left(1+2+\ldots+\mathrm{n}_{2}\right)+\left[\left(\mathrm{n}_{2}+1 \ldots\right.\right. \\ &\left.\quad+\left(\mathrm{n}_{2}+\mathrm{n}_{1}\right)\right] \\ & \text { (d) } \operatorname{ACCUXP}=\left(\mathrm{x}_{2}+2 \mathrm{x}_{2}+\ldots+\mathrm{n}_{2} \mathrm{x}_{2}\right)+ \\ & \quad\left[\left(\mathrm{n}_{2}+1\right) \mathrm{x}_{1}+\ldots .\left(\mathrm{n}_{2}+\mathrm{n}_{1}\right) \mathrm{x}_{1}\right]\end{aligned}$

(e) DISXP $=\mathrm{x}_{2}\left(1-\exp \left(-\mathrm{Bn}_{2}\right)\right)+$

$\mathrm{x}_{1} \exp \left(-\mathrm{Bn}_{2}\right)\left(1-\exp \left(-\mathrm{Bn}_{1}\right)\right.$

Discounted exposure ${ }^{18}$ assumes that the lung heals (or fibroses) at a rate $\mathrm{B}$, proportional to the current amount of damage. Thus a heavy exposure may have less effect on present lung function if it happened in the distant past than if it happened recently. The constant B is estimated by trial and error-that is, if the lung takes five years to repair half the damage then $\mathrm{B}=\log _{\mathrm{e}} 2 / 5$.

It was found that TOTXP and TOTYR showed the highest negative correlation with level of FEV and with radiographic category, and these indices were used in the subsequent analyses.

\section{CHEST RADIOGRAPHY}

Standard full size posteroanterior chest radiographs were obtained. Focus-film distance was six feet, and the exposure used was $70 \mathrm{KV}, 200-300 \mathrm{~mA}$ for $0 \cdot 3-0 \cdot 4 \mathrm{~s}$.

The profusions of small rounded and irregular opacities $^{3}$ were read for 1978 and re-read for 1968 by one expert observer who had not seen the films previously. The films were read side by side.

STATISTICAL PROCEDURES

The association between pulmonary function and various radiological changes such as size and shape of small opacities was examined by multiple regression analysis ${ }^{19}$ using the GENSTAT computer program ${ }^{20}$ to allow for any differences in age, height, and smoking habits between radiographically determined groups. For example, to examine the association between pulmonary function and irregular opacities we fitted an equation of the form $\mathrm{y}=\mathrm{a}+\mathrm{b}$ age $+\mathrm{c}$ height $+\mathrm{d}$ smo $+\mathrm{e}$ exsmo + f irreg

The variables smo, exsmo, and irreg are dummy variables, taking the value zero except that smo $=1$ if the subject is a smoker, exsmo $=1$ if the subject is an ex-smoker, and irreg $=1$ if the radiograph shows irregular opacities. The coefficients $a, b, c, d, e$, and $f$ are determined by multiple linear regression, together with their standard errors. The significance of a particular term is computed making the assumption that the ratio of an estimate to its standard error follows an approximate " $t$ " distribution. The mean values in the tables are $y=a+b$ (mean age) $+c$ (mean height), where a, b, c, are the estimated values of $a, b, c$ in the above model and thus the $y$ values are those predicted for non-smokers. To examine whether size (p, q, r) could account for the effects found for shape, firstly, table 4 was produced, showing no significant correlation between size and shape. Then two additional dummy variables were added to the above model. These were dump $=1$ if subject has p-type opacities and dumr $=1$ if the subject has r-type opacities, and both are zero elsewhere. The significance of the irregular opacities was not materially changed by the addition of these two variables, and similarly the significance of the size parameter was not changed compared with the model that contained dump and dumr but not irreg.

\section{Results}

RADIOGRAPHIC APPEARANCES

For subjects followed up in 1978 there was no radiographic progression of profusion of simple pneumoconiosis since 1969 (table 1). Fourteen men were found to have developed irregular opacities (table 2). Twelve developed ill-defined large opacities and 16 progressed mainly from ill-defined to well-defined

Table 1 Progression of profusion of small opacities between surveys

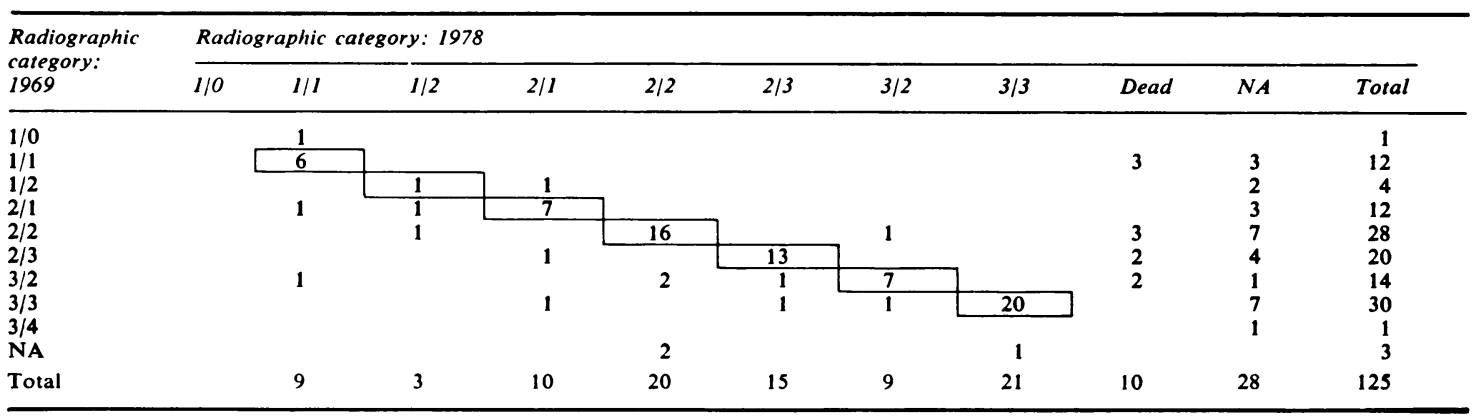

NA $=$ Radiograph not available. 
Table 2 Progression of irregular opacities between surveys

\begin{tabular}{|c|c|c|c|c|c|c|}
\hline \multirow{2}{*}{$\begin{array}{l}\text { Radiographic } \\
\text { category: } \\
1969\end{array}$} & \multicolumn{6}{|c|}{ Radiographic category: 1978} \\
\hline & $\boldsymbol{O}$ & $s$ & $t$ & Dead & $N A$ & Total \\
\hline $\mathbf{O}$ & 54 & $\mathbf{0}$ & 14 & 6 & 25 & 99 \\
\hline $\mathbf{s}$ & 1 & 2 & 0 & 0 & 0 & 3 \\
\hline$t$ & 1 & 0 & 12 & 4 & 3 & 20 \\
\hline NA & 1 & 0 & 2 & 0 & 0 & 3 \\
\hline Total & 57 & 2 & 28 & 10 & 28 & 125 \\
\hline
\end{tabular}

NA = Radiograph not available.

lesions (table 3). Subjects who developed large opacities were not recruited preferentially from those with the higher categories of simple pneumoconiosis. The cause of death in the 10 subjects who died between surveys was unrelated to the type or extent of the rounded opacities present in 1969 . The subjects who were seen at home after declining to attend at the laboratory were on average older than those who attended but the two groups were otherwise similar.

\section{PULMONARY FUNCTION, SMOKING, AND}

DUST EXPOSURE

Pulmonary function was related to smoking history and to exposure to coal dust (table 4). Subjects who were cigarette smokers in 1978 had a significantly lower $\mathrm{FEV}_{1}, \mathrm{FVC}$, and FEV/FVC and higher RV/ TLC, while ex-smokers had a lower $\mathrm{Tl}$ and $\mathrm{KCO}$ and higher RV/TLC compared with non-smokers. Total dust exposure was significantly inversely related to FVC and RPmax.

\section{SIMPLE PNEUMOCONIOSIS}

In 1978 the presence of $p$ opacities was associated with significantly lower values for $\mathrm{Tl}$ and $\mathrm{Kco}$ compared with subjects exhibiting q opacities (table 5); there was also a tendency toward a higher level of $\mathrm{C}_{\mathrm{E}}$.

Subjects with $\mathrm{r}$ opacities in 1978 also had a lower mean Kco compared with those having q opacities: additionally, they had a higher $R P_{1 L}$ and $R P_{50}$ and a
Table 4 Association of exposure and smoking on pulmonary function* 1978

\begin{tabular}{|c|c|c|c|}
\hline & $\begin{array}{l}\text { Regression } \\
\text { coefficient on total } \\
\text { exposure } \\
(T O T X P)(y r)\end{array}$ & $\begin{array}{l}\text { Current } \\
\text { smokers }\end{array}$ & Ex-smokers + \\
\hline 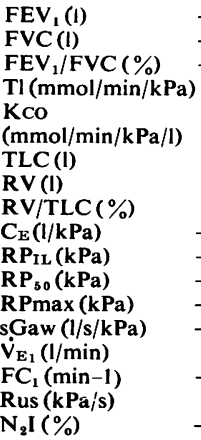 & $\begin{array}{c}-0.0033 \\
-0.0046 \dagger \\
-0.0145 \\
0.0006 \\
\\
0.0002 \\
0.0012 \\
0.0032 \\
0.0377 \\
-0.0002 \\
-0.0207 \dagger \\
-0.0097 \\
-0.0510 \dagger \\
-0.0001 \\
0.0163 \\
-0.0718 \\
0.00079 \\
-0.0098\end{array}$ & $\begin{array}{l}-0.53 \dagger \dagger \\
-0.44 \dagger \\
-7.39 \dagger \\
-1.09 \\
-0.16 \\
-0.06 \\
0.35 \\
6.3 \dagger \\
-0.04 \\
0.21 \\
0.49 \\
2.09 \\
-0.03 \\
-1.29 \\
14.5 \\
0.16 \\
-0.78\end{array}$ & $\begin{array}{c}-0.30 \\
-0.31 \\
-3.06 \\
-1.35 \dagger \\
\\
-0.20 \dagger \\
0.03 \\
0.42 \\
6.4 \dagger \dagger \\
-0.04 \\
0.07 \\
-0.01 \\
0.75 \\
-0.01 \\
-0.73 \\
-1.40 \\
0.063 \\
-0.62\end{array}$ \\
\hline
\end{tabular}

*After correcting for the effect of age and height.

$\dagger, \dagger+$ Significantly different from zero or non-smokers at respectively $5 \%$ and $1 \%$ levels.

¥Mean effect compared with non-smokers. For example, current smokers have a deficit in $\mathrm{FEV}_{1}$ of 0.531 compared with non-smokers.

tendency to lower $\mathrm{C}_{\mathrm{E}}$. There were no differences in magnitude of change in lung function between 1969 and 1978 between subjects with the several types of simple pneumoconiosis except for a greater fall in $\mathrm{RP}_{50}$ in subjects with $\mathrm{p}$ opacities; there may have been a technical explanation for this (see discussion).

\section{IRREGULAR OPACITIES}

Subjects with irregular opacities in 1978 were older and taller than those without. They had a significantly reduced $\mathrm{KCO}$ and $\mathrm{Tl}$ and a lower nitrogen slope (table 6). These indices contributed significantly to a discriminant function which distinguished subjects with irregular opacities from others with pneumoconiosis. The type of small rounded opacities present in 1969 did not appear to be related to the subsequent development of irregular opacities.

Table 3 Progression of large opacities between surveys

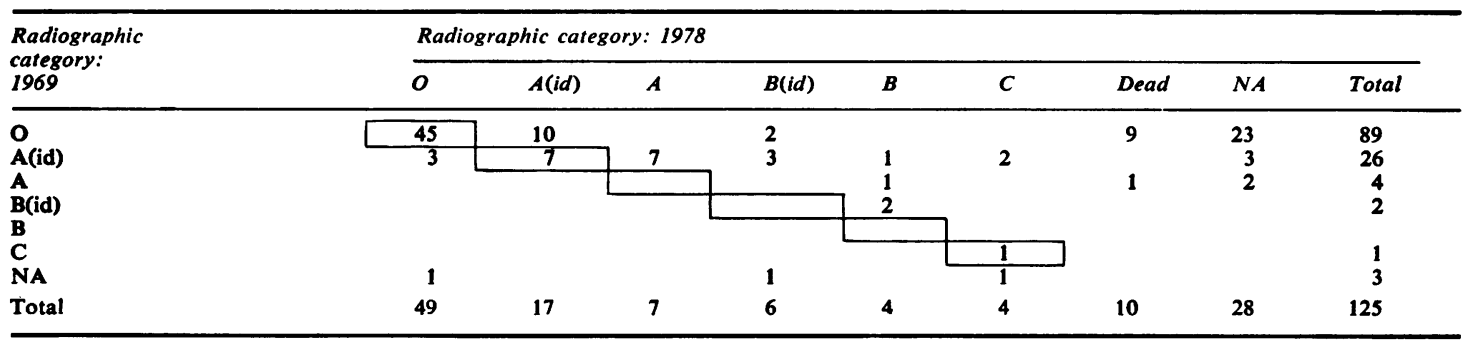

id $=$ Ill defined.

NA = Radiograph not available. 
Table 5 Association of type of small rounded opacity with pulmonary function* 1978

\begin{tabular}{|c|c|c|c|}
\hline & $p$ & $q$ & $r$ \\
\hline Noß & 19 & 53 & 12 \\
\hline Age $(y r)$ & $58 \cdot 5$ & $59 \cdot 5$ & $60 \cdot 0$ \\
\hline $\mathrm{Ht}(\mathrm{m})$ & $1 \cdot 70$ & $1 \cdot 67$ & 1.68 \\
\hline Total exposure (TOTXP) & $118 \cdot 5$ & $120 \cdot 8$ & $132 \cdot 6$ \\
\hline$\%$ smokers & 53 & 53 & 58 \\
\hline$\%$ ex-smokers & 26 & 19 & 33 \\
\hline $\mathrm{FEV}_{1}(\mathrm{l})$ & $2 \cdot 73$ & $2 \cdot 52$ & $2 \cdot 73$ \\
\hline FVC (I) & $3 \cdot 88$ & $3 \cdot 66$ & $3 \cdot 87$ \\
\hline $\mathrm{FEV}_{1} / \mathrm{FVC}(\%)$ & $70 \cdot 4$ & $68 \cdot 0$ & $70 \cdot 0$ \\
\hline $\mathrm{Tl}(\mathrm{mmol} / \mathrm{min} . \mathrm{kPa})$ & $8.05+\dagger$ & $9 \cdot 39$ & $8 \cdot 57$ \\
\hline $\mathrm{Kco}(\mathrm{mmol} / \mathrm{min} . \mathrm{kPa} . \mathrm{l})$ & $1 \cdot 32++$ & $1 \cdot 58$ & $1 \cdot 40 \dagger$ \\
\hline TLC (I) & $2 \cdot 26$ & $6 \cdot 23$ & $6 \cdot 40$ \\
\hline RV (I) & $2 \cdot 31$ & $2 \cdot 45$ & $2 \cdot 34$ \\
\hline RV $/$ TLC $(\%)$ & $36 \cdot 7$ & $38 \cdot 9$ & $36 \cdot 2$ \\
\hline $\mathrm{C}_{\mathrm{E}}(\mathrm{l} / \mathrm{kPa})$ & $0.38(16)$ & $0.33(46)$ & $0.27(10)$ \\
\hline $\mathbf{R P}_{I L}(\mathrm{kPa})$ & $7 \cdot 26(16)$ & $7 \cdot 11(46)$ & $8 \cdot 76+(10)$ \\
\hline $\mathrm{RP}_{50}(\mathrm{kPa})$ & $5 \cdot 26(16)$ & 4.69 (46) & $6 \cdot 26+t(10)$ \\
\hline RPmax (kPa) & $14 \cdot 7(16)$ & $16.9(46)$ & $18 \cdot 1(10)$ \\
\hline sGaw $(1 / \mathbf{s} / \mathbf{k P a})$ & $1 \cdot 4+t$ & $1 \cdot 1$ & $1 \cdot 1$ \\
\hline$\dot{\mathrm{V}}_{\mathrm{E}_{1}}(\mathrm{l} / \mathrm{min})$ & $33.9(12)$ & $31 \cdot 7(40)$ & $31 \cdot 6(7)$ \\
\hline $\mathrm{FC}_{1}(\min -1)$ & $102 \cdot 1(12)$ & $99 \cdot 8(40)$ & $95 \cdot 3(7)$ \\
\hline Rus $(\mathrm{kPa} / \mathrm{s})$ & 0.23 (15) & $0.23(42)$ & $0.27(10)$ \\
\hline $\mathrm{N}_{2} \mathrm{I}(\%)$ & $1 \cdot 14(16)$ & $1.79(49)$ & $2 \cdot 19(12)$ \\
\hline
\end{tabular}

*After correcting for the effects of age, height, and smoking category. $\S$ Three subjects classified as irregular only were not included in this table. Smaller numbers of subjects are shown in parentheses.

$\dagger, \dagger+S i g n i f i c a n t l y$ different from the q opacity group at respectively $5 \%$ and $1 \%$ levels.

Table 6 Association of irregular opacities with pulmonary function* 1978

\begin{tabular}{|c|c|c|}
\hline & $\begin{array}{l}\text { Irregular } \\
\text { opacities absent }\end{array}$ & $\begin{array}{l}\text { Irregular } \\
\text { opacities present }\end{array}$ \\
\hline No & 57 & 30 \\
\hline Age $(y r)$ & $58 \cdot 3$ & $62 \cdot 1$ \\
\hline $\mathrm{Ht}(\mathrm{m})$ & 1.67 & $1 \cdot 70$ \\
\hline Total exposure (TOTXP) & $118 \cdot 8$ & $130 \cdot 2$ \\
\hline$\%$ smokers & 56 & 48 \\
\hline$\%$ ex-smokers & 21 & 33 \\
\hline $\mathrm{FEV}_{1}(\mathrm{l})$ & $2 \cdot 58$ & $2 \cdot 56$ \\
\hline FVC (I) & $3 \cdot 71$ & $3 \cdot 74$ \\
\hline $\mathrm{FEV}_{1} / \mathrm{FVC}(\%)$ & $68 \cdot 8$ & $67 \cdot 8$ \\
\hline $\mathrm{Tl}(\mathrm{mmol} / \mathrm{min} . \mathrm{kPa})$ & $9 \cdot 54$ & $8 \cdot 32 \dagger$ \\
\hline $\mathrm{KCO}(\mathrm{mmol} / \mathrm{min} . \mathrm{kPa} . \mathrm{l})$ & $1 \cdot 58$ & $1 \cdot 42+t$ \\
\hline TLC (I) & $6 \cdot 30$ & $6 \cdot 18$ \\
\hline$R V(1)$ & $2 \cdot 49$ & $2 \cdot 30$ \\
\hline RV/TLC (\%) & $39 \cdot 2$ & $36 \cdot 8$ \\
\hline $\mathrm{C}_{\mathrm{F}}(\mathrm{l} / \mathrm{kPa})$ & $0 \cdot 336(55)$ & $0 \cdot 329(20)$ \\
\hline$R P_{I L}(k P a)$ & $7.08(55)$ & $7 \cdot 41(20)$ \\
\hline$R P_{50}(k P a)$ & $4 \cdot 71(55)$ & $5.03(20)$ \\
\hline$R P \max (\mathbf{k a})$ & $16 \cdot 0(55)$ & $17.9(20)$ \\
\hline sGaw (1/s.kPa) & $1 \cdot 16$ & $1 \cdot 19$ \\
\hline$\dot{\mathrm{V}}_{\mathrm{E}_{1}}(\mathrm{l} / \mathrm{min})$ & $31 \cdot 6(40)$ & $32 \cdot 2(20)$ \\
\hline $\mathrm{FC}_{1}(\min -1)$ & $97 \cdot 2(40)$ & $105 \cdot 7(20)$ \\
\hline Rus ( $(\mathrm{Pa} / \mathrm{s})$ & $0 \cdot 29(40)$ & $0 \cdot 11(20)$ \\
\hline $\mathrm{N}_{2} \mathrm{I}(\%)$ & 1.49 & $2 \cdot 31$ \\
\hline
\end{tabular}

*After correcting for the effects of age, height, and smoking category. $\dagger, \dagger+$ Significantly different from the "irregular opacities absent" group at respectively $5 \%$ and $1 \%$ levels.

Subjects with irregular opacities were not unusual in their smoking habits or the extent to which their score for bronchitis or breathlessness increased between surveys. The rate of decline of $\mathrm{Tl}$ and $\mathrm{KcO}$ tended to be greater in subjects who developed
Table 7 Pulmonary function in 1969 in relation to the subsequent development of large opacities

\begin{tabular}{|c|c|c|c|}
\hline & $\begin{array}{l}\text { Large } \\
\text { opacities } \\
\text { present } 1969 \\
\text { and } 1978\end{array}$ & $\begin{array}{l}\text { Large } \\
\text { opacities } \\
\text { present } 1978 \\
\text { absent } 1969\end{array}$ & $\begin{array}{l}\text { Large } \\
\text { opacities } \\
\text { absent } 1969 \\
\text { and } 1978\end{array}$ \\
\hline No & 24 & 12 & 46 \\
\hline Age (yr) & $53 \cdot 1$ & $51 \cdot 3$ & $51 \cdot 5$ \\
\hline Total exposure (TOTXP) & $132 \cdot 1$ & $119 \cdot 6$ & $113 \cdot 8$ \\
\hline $\mathrm{FEV}_{1}(\mathrm{I})$ & $2 \cdot 34$ & $2 \cdot 46$ & $2 \cdot 58$ \\
\hline FVC (I) & $3 \cdot 56$ & $3 \cdot 77$ & $3 \cdot 70$ \\
\hline $\mathrm{FEV}_{1} / \mathrm{FVC}$ & $65 \cdot 80$ & $69 \cdot 75$ & 64.09 \\
\hline $\mathrm{Tl}(\mathrm{mmol} / \mathrm{min} . \mathrm{kPa})$ & $8 \cdot 36$ & $9 \cdot 12$ & 8.93 \\
\hline $\operatorname{Kco}\left(T l / V_{A}\right)$ & $1 \cdot 41$ & $1 \cdot 41$ & 1.49 \\
\hline TLC (He) (I) & $6 \cdot 18$ & $6 \cdot 72$ & $6 \cdot 22$ \\
\hline RV (1) & $2 \cdot 33$ & $2 \cdot 64$ & $2 \cdot 22$ \\
\hline$C_{E}(1 / k P a)$ & $0 \cdot 355$ & $0 \cdot 232$ & $0 \cdot 341$ \\
\hline$R P_{I L}(k P a)$ & $5.65+$ & $8 \cdot 38+$ & 6.94 \\
\hline$R P_{50}(k P a)$ & $3 \cdot 44$ & $4 \cdot 78$ & $4 \cdot 02$ \\
\hline sGaw $(\mathrm{l} / \mathrm{s} / \mathrm{kPa})$ & $1.78 \dagger$ & $1 \cdot 64 t \dagger$ & $2 \cdot 38$ \\
\hline$\dot{\mathrm{V}}_{\mathrm{E}_{1}}(\mathrm{l} / \mathrm{min})$ & $34 \cdot 80$ & $32 \cdot 74$ & $34 \cdot 56$ \\
\hline $\mathrm{FC}_{1}(\min -1)$ & $104 \cdot 5$ & 96.40 & $101 \cdot 3$ \\
\hline
\end{tabular}

Statistical significance of difference from subjects with no large opacities in 1969 or $1978+p<0.05+t p<0.01$. For symbols and abbreviations see text.

Table 8 Type of small opacity and development of large opacities

\begin{tabular}{lrrrc}
\hline & $p$ & $q$ & $r$ & Total \\
\hline Large opacity developed & 5 & 4 & 3 & 12 \\
Large opacity did not develop & 8 & 34 & 3 & 45 \\
Total & 13 & 38 & 6 & $>57^{*}$
\end{tabular}

* Remaining radiographs were considered to have large opacities in 1969. Result shows that significantly fewer subjects with q opacities developed large opacities, compared with $p$ and $r\left(x^{2}{ }_{2}=7.93\right.$, $\mathrm{p}<0.02$ )

Table 9 Relationship between type and shape of small opacities in 1978

\begin{tabular}{llrrrl}
\hline & \multicolumn{2}{l}{ Rounded } & & \\
\cline { 2 - 6 } & $O$ & $p$ & $q$ & $r$ & Total \\
\hline Irregular absent & 0 & 14 & 8 & 35 & 57 \\
Irregular present & 3 & 5 & 4 & 18 & 30 \\
Total & 3 & 19 & 12 & 53 & 87 \\
\hline
\end{tabular}

For the 84 radiographs with small rounded opacities, contingency table analysis gives $x_{2}^{2}=0.38, p>0.1$-that is, no correlation between size and shape of small opacity.

irregular opacities between surveys compared with those who did not, but the difference did not approach statistical significance.

PROGRESSIVE MASSIVE FIBROSIS

Subjects who had large opacities in 1969 or who subsequently developed large opacities had significantly lower mean values for sGaw than the subjects with simple pneumoconiosis in 1978 (table 7). Subjects with large opacities present in 1969 had a significantly lower mean $R_{P_{1 L}}$ and subjects who developed large opacities between 1969 and 1978 a significantly higher $R_{P_{1 L}}$ compared with subjects 
without large opacities in 1978. The presence of large opacities categories B and C in 1978 was associated with a significantly lower mean $\mathrm{FEV}_{1}, \mathrm{FEV}_{1} / \mathrm{FVC}$, and $C_{E}$ and a tendency to lower sGaw and $\mathrm{Tl}$ compared with the other subjects. The pulmonary function of subjects with category A large opacities did not differ significantly from that of subjects with simple pneumoconiosis alone. The subjects with $\mathrm{p}$ or $r$ opacities showed a greater attack rate of PMF than did the subjects with q opacities (table 8). There was no association, however, between the type of simple pneumoconiosis and the presence or absence of PMF in either 1969 or 1978 (table 9).

\section{Discussion}

The coal miners in this study, who were all working in 1969 , were then considered by three readers to have well-established radiographic simple pneumoconiosis without PMF or conspicuous irregular opacities. Among these subjects those with predominant p-type opacities had some of the physiological features of emphysema, including a reduced $\mathrm{KCO}$ and increased static lung compliance. Subsequently one of the subjects developed the features of cystic lung, and this observation led to the present follow-up study.

The methods used in the two studies were similar but the operators were different. This was probably not important except in the case of the recoil pressure, where the technique for reading the oscilloscope image used in 1969 was such as to lead to systematic underestimation; $C_{E}$ was probably not affected. In addition, in 1978 the radiographs for 1969 and 1978 were read side by side by one highly experienced observer who had not seen the films previously. This process led to the reclassification as PMF of 33 of the 1969 films previously read as simple pneumoconiosis; 28 were read as ill-defined large opacities, four as category $\mathrm{A}$, and one as category $\mathrm{C}$. On the second occasion the films were read for small irregular opacities and 23 cases were so identified, although in general the lesions were not extensive; this was to be expected as in the initial selection of subjects in 1969 those whose radiographs showed a pronounced reticular pattern were excluded.

The mortality experience of 10 deaths in the subsequent nine years among the 125 men seen in 1969 is unexceptional, but it is of interest that three were read as having irregular opacities and of these, two died a respiratory death. The 22 subjects seen at home were older but were similar to those who were studied in detail in all other respects including ventilatory capacity and respiratory symptoms. The lapse rate was only $3 \cdot 2 \%$. Thus the present findings accurately reflect the status in 1978 of the subjects seen in 1969; whether or not the findings are typical of all men with advanced simple pneumoconiosis in South Wales can be established only by study of complete populations as has been done by Cochrane et al.21

The present results show the expected increased airway obstruction in smokers ${ }^{4}$ and of FVC in proportion to exposure to coal dust. ${ }^{22}$ The exsmokers also had impaired lung function, which may have contributed to their stopping smoking. These associations as well as those with age, stature, and bronchitis were taken into account when considering the relationship of lung function to radiographic category.

The finding that among men with simple pneumoconiosis those with p-type opacities had a lower $\mathrm{Tl}$ and $\mathrm{KCO}$ and a tendency towards a higher compliance compared with men having q opacities is consistent with the earlier studies. ${ }^{23}$ The exercise ventilation was also rather higher than in the $q$ cases, but unlike in a previous investigation ${ }^{24}$ this difference was not significant. In addition, compared with 1969 and after allowing for the systematic difference in recoil pressure between the two surveys, the results of the follow-up study showed a significantly greater decline in recoil pressure in the $p$ cases. The previous result was interpreted as evidence for focal emphysema and the present findings are consistent with this view. There is an urgent need for information on the morbid anatomy of the lung in these cases; a procedure for its collection has been set up and material is now accumulating.

Among men with $\mathrm{r}$ opacities the reduced $\mathrm{KcO}$ associated with an increase in recoil pressure and a tendency towards a reduction in lung compliance is evidence that the lung function is more affected by the occupational exposure than in men with $q$ opacities. The pattern and extent of abnormality is suggestive of mild diffuse fibrosis or space occupying lesions. The absence of changes in exercise ventilation or in total lung capacity militate against the abnormality being of functional significance. Its presence, however, suggests that the different radiographic abnormalities of simple pneumoconiosis reflect underlying structural differences which, at the extremes, range from very small to largish nodules of accumulated dust and from diffuse focal emphysema to diffuse fibrosis. These abnormalities to some extent coexist and their physiological features overlap. Thus the differences that have been observed may be of greater consequence than their small magnitude would suggest; they may also reflect in part the initial condition of the lung. In addition they are associated with different propensities for developing PMF. The explanation of this finding requires a greater understanding of the mechanism of development of PMF than is at present available. It 
will need to take into account that while the attack rates differed between the radiographic types of simple pneumoconiosis the distribution of types among the subjects with PMF was similar to that for men with simple pneumoconiosis. The present study confirms the absence of physiological abnormality in men with $A$ shadows other than that associated with small opacities. ${ }^{4}$ Among those with B and C opacities in 1978 there was a significant degree of airway narrowing, which in 1969 also extended to those who subsequently developed large opacities between the two surveys. The presence of large opacities was associated with changes in lung elasticity including an increased recoil pressure (1969) and reduced lung compliance (1978); the transfer factor was somewhat reduced. The latter features are consistent with loss of lung tissue secondary to the development of space occupying lesions; the former may reflect an associated distortion and narrowing of the airways preceding the respiratory symptoms that are a feature of the established condition.

Men with irregular opacities were older and taller than the others. After allowing for this and for changes in lung function associated with pneumoconiosis and smoking they had a reduced transfer factor and Kco. This finding, which is evidence for loss of functional lung tissue, was predicted in the earlier study ${ }^{1}$ where it was noted that the reduction in transfer factor with p-type simple pneumoconiosis observed by Billiet and colleagues was greater than for the present subjects; the two studies differed in that the former included men whose radiographs were read as having profuse irregular opacities-whereas the presence of extensive irregularities was an indication for exclusion from entry to the present investigation. In addition, in the Belgian study the irregular opacities appeared to be more prevalent among men with p-type opacities. This association was not observed in the present study. Nor was there interaction between irregular opacities and smoking leading to increased airways obstruction as observed by Amandos et al. ${ }^{25}$ The decreased nitrogen index in those with irregular opacities may be due to diffuse fibrosis widening the small lung airways. However, there were no clear-cut parallel changes in total lung capacity, compliance, recoil pressure, and upstream resistance, which suggests the presence of additional emphysema and is consistent with a recent preliminary study of the underlying pathology. ${ }^{26}$ There is need for more information before the status of irregular opacities can be established with certainty.

We are indebted to many colleagues at the MRC Pneumoconiosis Unit for their help in this study including in particular Dr J C Gilson, who read the chest radiographs taken by Miss S Latham; Miss C
Exall, who contacted some of the subjects; Mr M J Saunders, Mr G R Johnson, Mrs I Ashton, Mrs J M Robson, and Mrs G Collins, who made some of the physiological measurements; and Mrs P E J Harding and Mrs E M Humphries who typed the manuscript. Requests for reprints should be addressed to Mrs Bevan.

\section{References}

${ }^{1}$ Cotes JE, Deivanayagam CN, Field GB, Billiet L. Relation between type of simple pneumoconiosis ( $p$ or $m$ ) and lung function. In: Walton WH, ed. Inhaled particles III. Old Woking: Unwin Bros, 1971 :633-43.

${ }^{2}$ Seaton A, Lapp NL, Morgan WKC. Relationship of pulmonary impairment in simple coalworkers' pneumoconiosis to type of radiographic opacity. $B r J$ Ind Med 1972;29:50-5.

${ }^{3}$ International Union against Cancer Committee. UICC/ Cincinnati classification of the radiographic appearances of pneumoconiosis. A comparative study by the UICC Committee. Chest 1970;58:57-67.

4 Cotes JE. Lung function. Assessment and application in medicine. 4th ed. Oxford: Blackwell, 1979.

${ }^{5}$ Musk AW, Bevan C, Campbell MJ, Cotes JE. Factors contributing to the clinical grade of breathlessness in coalworkers' pneumoconiosis. Bull Eur Physiopathol Respir 1979;15:343-53.

- Medical Research Council Committee on Research into Chronic Bronchitis. Instructions for use of the questionnaire on respiratory symptoms. Dawlish, Devon: WJ Holman, 1966.

${ }^{7}$ McDermott M, McDermott TJ. Digital incremental techniques applied to spirometry. Proc $R$ Soc Med 1977; 70:169-71.

${ }^{8}$ Ogilvie CM, Forster RE, Blakemore WS, Morton JW. A standardized breath holding technique for the clinical measurement of the diffusing capacity of the lung for carbon monoxide. J Clin Invest 1957;36:1-17.

- Roughton FJW, Forster RE. Relative importance of diffusion and chemical reaction rates in determining rate of exchange of gases in the human lung. J Appl Physiol 1957;11:290-302.

${ }^{10}$ Dubois AB, Botelho SY, Comroe JH, Jr. A new method for measuring airway resistance in man using a body plethysmograph. Values in normal subjects and in patients with respiratory disease. J Clin Invest $1956 ; 35$ : 327-35.

${ }^{11}$ Reynolds JA, McKerrow CB. A multiplex cathode-ray-tube display with digital readout for a body plethysmograph. Med Biol Eng 1973;11:268-74.

12 Milic-Emili J, Mead J, Turner JM, Glauser EM. Improved technique for estimating pleural pressure from esophageal balloons. J Appl Physiol 1964;19:207-11.

${ }^{13}$ Hart A, McKerrow CB, Reynolds JA. A method of using an $x-y$ recorder in measuring the lung compliance. $J$ Physiol (Lond) 1966;184:50P-2P.

${ }^{14}$ Colebatch HJH, Finucane KE, Smith MM. Pulmonary conductance and elastic recoil relationships in asthma and emphysema. J Appl Physiol 1973;34:143-53.

${ }^{15}$ Saunders MJ, James PJ. Digital respiratory rate and ventilation recorder. Med Biol Eng Comput 1978;16: 337-8.

${ }^{16}$ McKerrow CB, Reynolds JA. A versatile respiratory integrator. J Physiol (Lond) 1968 ;200:13-5P.

17 Comroe JH, Jr, Fowler WS. Detection of uneven ventilation during a single breath of $\mathrm{O}_{2}$. Am J Med $1951 ; 10$ : 408-13.

18 British Thoraic and Tuberculosis Association Committee. 
Opportunist mycobacterial pulmonary infection and occupational dust exposure. An investigation in England and Wales. Tubercle 1975;56:295-309.

10 Kendal MG. Multivariate analysis. London: Ch Griffin, 1975.

${ }^{20}$ Alvey NG, Banfield CF, Baxter RI, et al. A general statistical program. Harpenden: Statistics Department, Rothamsted Experimental Station, 1977.

${ }^{21}$ Cochrane AL, Haley TJL, Moore F, Hole D. The mortality of men in the Rhondda Fach. Br J Ind Med 1979;36: 15-22.

22 Rogan JM, Attfield MD, Jacobsen M, Rae S, Walker DD, Walton WH. Role of dust in the working environment in development of chronic bronchitis in British coalminers. Br J Ind Med 1973;30:217-26.
${ }^{23}$ Lyons JP, Clarke WG, Hall AM, Cotes JE. Transfer factor (diffusing capacity) for the lung in simple pneumoconiosis of coal workers. Br Med J 1967;iv:772-4.

${ }^{24}$ Cotes JE, Field GB. Lung gas exchange in simple pneumoconiosis of coal workers. Br J Ind Med 1972;29: 268-73.

${ }^{25}$ Amandos HE, Lapp NL, Jacobsen C, Reger RB. Significance of irregular small opacities in radiographs of coalminers. Br J Ind Med 1976;33:13-7.

${ }^{26}$ Cockcroft AE, Wagner JC, Seal RME, Lyons JP, Campbell MJ. Irregular opacities in coal workers' pneumoconiosis-correlation with pulmonary function and pathology. In: Walton WH, ed. Inhaled particles $V$. Old Woking: Unwin Bros, (in press). 
periods if anything but gross effects are to be shown to be statistically significant, while Fletcher et $a l^{4}$ have discussed a wide range of factors that can cause such analyses to be misleading. Nevertheless, had a pronounced dose-effect relationship been observed for these 70 men over the period of four years it could have been regarded as the first indication of a chronic pulmonary problem.

In practice, the differences observed among the various exposure, smoking, and atopic categories are so small, by comparison with the variability in the data, as to make any interpretation extremely premature.

The overall mean rate of loss of $\mathrm{FEV}_{1}$ for the 70 men, $46 \mathrm{ml} /$ year, is in line with published figures for studies inclusive of smokers, and the mean loss rate for gas transfer factor is close to its predicted value. The mean rate of loss of FVC, $76 \mathrm{ml} /$ year, is high but, if it is correlated with anything, it is with smoking habits rather than with exposure category or atopic status.

Probably symptoms are produced as a reaction to exposure to the lipopolysaccharide (endotoxin). It has been shown experimentally in animals that Pruteen is capable of activating complement by the alternative pathway, but attempts to show $\mathrm{C}_{3}$ conversion in exposed men have so far been unsuccessful. Attempts to reproduce the eye symptoms in rabbits or guinea-pigs by exposure to direct contact with the dust have also been unsuccessful (G E Davies, personal communication).
The results have shown that Pruteen can be produced and handled without adverse effects on health, provided that adequate measures are taken to prevent exposure to high concentrations of dust.

I thank Dr G E Davies, ICI Central Toxicology Laboratory, who carried out the immunological work, and Dr G M Paddle, medical statistician, ICI Central Medical Group, who did the statistical analyses, for their invaluable advice and support. I also thank Dr P T Monard, medical officer, ICI, for his help in designing the programme and Dr C A C Pickering, Wythenshawe Hospital, for his guidance and help.

Finally, I thank the staff of the Billingham medical department and the men who participated in the survey for their willing co-operation and interest.

\section{References}

${ }^{1}$ Parkes WR. Occupational lung disorders. London: Butterworths, 1975:392.

2 Juniper CP, How MJ, Goodwin BFJ, Kinshott AK. Bacillus subtilis enzymes: a 7-year clinical, epidemiological and immunological study of an industrial allergen J Soc Occup Med 1977;27:3-12.

${ }^{3}$ Berry G. Longitudinal observations, their usefulness and limitations with special reference to the forced expiratory volume. Bull Physio-path Resp 1974;10:643-55.

${ }^{4}$ Fletcher C, Peto R, Tinker C, Speizer FE. The natural history of chronic bronchitis and emphysema. Oxford: Oxford University Press, 1976.

\section{CORRECTIONS}

\section{Healthy worker effect in the total Finnish population (May 1980)}

On page 181 the last paragraph should read: "Of the 4028 who stayed within the same occupational group, 151 died" as is shown in table 4 .

\section{A study of the mortality of Cornish tin miners (November 1981)}

The recommended standard for men exposed to radon in underground air should have read four working level months (p. 380). The conclusions of the paper are unaffected by this error.
Relationship between type of simple coalworkers' pneumoconiosis and lung function. A nine-year followup study of subjects with small rounded opacities (November 1981)

The authors regret that in their tables 4-7 the units of compliance and recoil pressure while reported to be in SI units were in fact given in traditional units; to make the conversion the numerical values for compliance and recoil pressure should respectively be multiplied by and divided by 10 . 